\title{
Modelo superestructural de la noticia en Televisión
}

\author{
Lluís MAS MANCHÓN \\ Universitat Autònoma de Barcelona \\ lluis.mas.manchon@gmail.com
}

Recibido: $16 / 09 / 2010$

Aceptado: 28/03/2011

\begin{abstract}
Resumen
Existe un modelo propio pragmático de la noticia en televisión que conecta los aspectos formales, textuales y vocales del discurso. Desde una perspectiva funcionalista, sistémica y plenamente comunicológica, definimos la noticia como un mensaje eficaz y perfectamente estructurado en estos tres niveles. Esto implica que el formato que adopta toda noticia determina un texto perfectamente estructurado en párrafos, frases y palabras, que a su vez determina una locución muy caracterizada por unas formas expresivas orales. Nuestro trabajo de tesis se ha centrado en analizar una gran muestra y encontrar cuáles son esas formas. En este artículo, presentamos el modelo que integra la estructura de la noticia en tres niveles: presentamos sus principios de aplicación y hacemos un primer análisis integral de una noticia.
\end{abstract}

Palabras clave: Noticia, estructura discurso, locución, prosodia.

\section{Superstructural Model for TV News}

\begin{abstract}
There exist a specific model for the pragmatics of the TV news that connects the formal, textual and vocal aspects of discourse. From a functionalist, systemic and fully communication approach, the piece of news is defined as an efficient message perfectly structured in three levels. This implies that the format every piece of news take determine an accurate structure for the text in paragraphs, phrases and words, and at the time determine an announcing very characterized by come oral expressive forms. Our thesis work has focused in analyzing a great sample and finding which those forms are. Here, a model is presented to integrate the piece of news in three levels: its principles o structuring and a primary analysis of an example of piece of news.
\end{abstract}

Key words: Piece of news, structure, discourse, locution, prosody.

Referencia normalizada

MAS MACHÓN, Lluís (2011): “Modelo superestructural de la noticia en Televisión”. Estudios sobre el mensaje periodístico. Vol. 17, núm. 1, págs.: 95-116. Madrid, Servicio de Publicaciones de la Universidad Complutense.

Sumario: 1. Introducción. 2. Propuesta epistemológica y marco teórico. 2.1. Discurso informacional. 2.2. Discurso textual. 2.3. Discurso vocal. 3. El modelo. 3.1. Aplicación del modelo. 3.2. Análisis. 3.3. Resultados. 4. Discusión. 5. Conclusión. 6. Referencias bibliográficas.

\section{Introducción}

La forma en que los presentadores de informativos de televisión "hablan” la noticia debería ser lo menos casual posible y lo más ajustada a un modelo estructural y estratégico. Esta estructura tendría un nivel 0 consistente en el contenido o semántica diferencial de cada noticia, con una contribución 0 a ese modelo; y tendría niveles 1 , 2 y 3, cada uno de los cuales insuflaría formas estables a la expresión de la noticia y todos en su conjunto configurarían la estructura discursiva reconocible 
de la misma. La integración de los tres niveles en la noticia como estructura está en función de los objetivos generales y parciales del emisor.

Los objetivos de un proceso de comunicación están representados por la función discursiva de los elementos que pone en liza el emisor en cada nivel de elaboración del mensaje, por lo que cada nivel no es sino un estado de complejidad y contribución a la función. Desde una perspectiva comunicológica (RoDRíGuEZ BRAVO, 2003), el emisor de un proceso masivo de comunicación:

1. Planifica unos objetivos comunicativos,

2. Que serán alcanzados mediante la manipulación física de uno o varios aspectos físicos de un mensaje,

3. Si con ello se consiguen unos efectos asociados.

A partir de aquí, puesto que los informativos son un proceso de comunicación con una función discursiva rigurosa y exacta, de la que conocemos perfectamente sus modos de transmisión y procesamiento, estamos en condiciones de modelizar el mensaje físico de la noticia a partir de sus tres fases claves de elaboración: la selección de la información noticiosa (nivel 1), la redacción del texto que será "leído" en plató (nivel 2) y la enunciación oral de ese texto por parte del presentador (nivel 3). Estos tres niveles son solidarios entre sí, por lo que las decisiones sobre sus componentes afectarán a los otros dos niveles y a la estructura en su conjunto. Por poner un ejemplo reduccionista de uno de esos componentes, puestos en el caso de un informativo sensacionalista que intenta informar sobre una atentado, en el nivel 1 se podría elegir como aspecto noticioso principal "el estado crítico de los heridos graves" -y no tanto "la autoría, el lugar, las circunstancias... del atentado"-, lo cual determinaría que el nivel 2 se inundara de palabras dantescas para la descripción de la escena y el estado de los heridos, desembocando en una enunciación oral (nivel 3) de ritmo dramático y énfasis en esas palabras-clave (por ejemplo: "charco de sangre”, "múltiples fracturas", "estado crítico", etc.).

Por lo tanto, este modelo consiste en la formulación exhaustiva de las formas expresivas de cada nivel. El nivel 1 se compone de los rasgos formales de la información noticiosa, y viene determinado por las marcas del género informativo, la estructura temática que se configura y el tipo de información tratada (nueva, vieja o mediada). El nivel 2 se compone de los rasgos textuales del guión de la noticia, por lo que viene definido por una macroestructura (formato y estilo del texto), una microestructura (léxico y lenguaje utilizados en el mismo) y una retórica del género (texto para ser expuesto formal o informalmente, o dialogado). En tercer lugar, el nivel 3 es la enunciación oral de la noticia y se configura a partir de tres componentes claves: el ritmo de exposición de la información, el acento sobre cierta información del discurso y el énfasis global durante la enunciación. Este modelo nace de la investigación aplicada de las prácticas locutivas en los informativos, con el objetivo de hacerlas más rigurosas y efectivas, y evitar así la cantinela y otras disfunciones de locución. Para ello, nuestra línea de investigación ha tratado de encontrar qué variaciones vocales del presentador son estructurales del tipo de discurso, el tipo de información, el nivel de formalidad, las intenciones informativas 
e ideológicas, etc. Así, hemos definido los modelos entonativos de la noticiaª el tipo de palabras-clave que se enfatizan (MAS MANCHón, 2010a), el uso retórico de la noticia (Ib., 2010b) y las formas prosódicas típicas de las fases de la noticia (Ib., 2008), entre otros.

En este artículo, presentamos el sustento teórico y metodológico de toda esta línea de investigación y la versión definitiva y general del Modelo Superestructural de la Noticia, compuesto de tres tipos de discursos contenidos mutuamente: formal, textual y vocal. En primer lugar, recorremos el marco teórico general de nuestra propuesta epistemológica y presentamos los axiomas o líneas maestras del modelo. Para ello conectaremos teorías del periodismo y de la información (estudios de género, formatos y lenguajes de la noticia) con teorías del procesamiento de la información de la lingüística computacional. A partir de aquí, nos centraremos en la formulación teórica de los tres niveles estructurales del mensaje noticia -formal (1), textual (2) y expresivo (3)-, y, por último, aplicaremos el modelo a un ejemplo de noticia aparecida en televisión.

\section{Propuesta epistemológica y marco teórico}

Actualmente, los medios de comunicación de masas no sólo son uno de los principales agentes del tejido social, sino que son su causa directa y contribuyen a su desarrollo: la sociedad mediática o de la información. Debido a la interrelación entre medios y contexto social, constantemente se reciben flujos de información estructurada y desestructurada, a partir de los cuales los medios generan mensajes estructurados llamados noticia. Existen por tanto tres fuentes de información noticiosa que inician el proceso de elaboración y transmisión de la noticia:

1. La realidad como fuente de "explosiones" noticiosas "naturales".

2. El contexto social o isotopía de la noticia.

3. La agenda-setting o agenda de los medios.

No obstante, estas fuentes de información no son un punto iniciático absoluto, sino que, como veremos, participan de todo el proceso de transmisión y procesamiento de la noticia. Ese bucle constante e inacabable sólo tiene sentido en procesos de comunicación de éxito.

Esta es una visión eminentemente sistémica de la comunicación (BERTALANFFY, 1968, 1986). Porque cada agente que participa en la elaboración de un mensaje (una noticia, por ejemplo) estará contribuyendo de forma parcelada pero sincrética a la configuración de unidades de significación, de forma que, haciendo una libre interpretación de la Teoría Matemática de la Comunicación (SHANon y WeAver, 1981), tomamos el mensaje como una suma de unidades de información cada una de las cuales debe ser transmitida exitosamente para el buen procesamiento de la globalidad. Así por ejemplo, aunque una noticia de televisión tiene infinitos códigos desde los códigos lingüísticos hasta los culturales y morales, e incluso tecnológicos-, a nosotros nos interesan las unidades informativas de procesamiento, que se integran

${ }^{1}$ Estos modelos han sido desarrollados para tres idiomas (catalán, español y portugués) en el marco de la tesis doctoral "Modelos Entonativos para la Segmentación Automática de los Programas Informativos en Unidades-Noticia”, dirigida por Ángel RodríguEz Bravo. 
en estructuras de la parte de la noticia que nos interese modelizar. En nuestro caso, se trata de los códigos expresivos vocales, cuya variabilidad significativa en la noticia se limita a indicar la urgencia, relevancia, emotividad, moralidad... de la información, ya que nunca antes han sido tratados y su función discursiva es primordial, y dependiente de una estructura integral -formal y textual- de la noticia. No en vano, el proceso de comunicación de la noticia tiende necesariamente a la eficiencia máxima.

Es así como el proceso de transmisión de la noticia en televisión es un sistema de agentes y procesos que configuran formas expresivas de procesamiento, que serán estables y de éxito en virtud de una entropía reducida a mínimos. Si entendemos por entropía la variabilidad que pueden tomar las unidades de información de un mensaje para provocar unos efectos previstos de comunicación, el periodista podrá ser más ambicioso en sus objetivos comunicativos cuanto menor sea esta entropía. En otras palabras, un buen periodista tenderá a codificar el mensaje de forma unívoca, para lo cual utilizará preferentemente rasgos formales, textuales y vocales integrados en unidades de las que intuye sus efectos específicos. Con nuestro modelo, no sólo optimizaría la realización vocal de la noticia, sino la parte de la realización formal y textual que tiene directamente que ver con la vocal. Mejoraría, en definitiva, la eficacia comunicativa de la noticia.

Un abordaje funcionalista, comunicológico y lingüístico de la cuestión (XU, 2004) sitúa el punto de partida de nuestro trabajo en el proceso de creación de la noticias y hasta su presentación oral en plató. Para empezar, el periodista adopta tres roles diferentes para encargarse de las tres fases de elaboración de la noticia en función del tipo de procesamiento (Westley y McLean, 1957). Tratemos pues el resultado de esas tres fases como discursos independientes:

1. Gatekeeper: selección de la información --> Discurso Informacional.

2. Redactor: redacción del texto --> Discurso Textual.

3. Presentador: locución de la noticia --> Discurso Oral.

Estudiemos cada discurso como un proceso funcional en que se tienen unos objetivos. Construimos a continuación el marco teórico de estos tres discursos a partir de los modos de transmisión y procesamiento de la información noticiosa en televisión.

\subsection{Discurso informacional}

Todo discurso gestiona información destinada a que alguien la capte. Ahora bien, ¿de qué tipo de información se trata? ¿Cuánta información puede transmitirse? ¿Qué organización discursiva se le da a esa información para que sea captada? Evidentemente, la primera pregunta se refiere al nivel de estructuración (elaboración primaria) de la información; la segunda a la selección de la información; y la tercera es conocer qué proceso perceptivo decisivo determina la captación de la información. En general, el periodista sabe que tiene que crear un producto para un género muy específico (el informativo televisivo), cuyo objetivo de comunicación es la transmisión de información verídica, relevante, actual, próxima, espectacular... Por lo tanto, el nivel de invención exnovo de la información es 0 , y todo lo que el gatekeeper debe hacer es gestionar la información que le llega. 
Por tanto, en primer lugar respondemos a la primera pregunta. El gatekeeper indaga sobre las posibilidades de que la información que le llega se convierta en noticia según los cuatro tipos de eventos susceptibles de serlo (GomIs, 1991: 114: 154):

- Eventos explosiones: sucesos únicos, imprevisibles y naturales (atentados, catástrofes, fenómenos naturales, etc.).

- Eventos apariciones: son los pseudoeventos, o eventos que ocurren para que los medios estén: declaraciones, conferencias, actos culturales, partidos de fútbol..., que ocurrirían sin la presencia de los medios pero que no serían lo mismo y no serían noticia. Sólo son noticia en el momento de su difusión mediática.

- Eventos resultados: cuando cualquier evento noticioso (explosión o aparición) ya ha sido noticia, todas las informaciones que genere a partir de ese momento ya serán mediáticas en su nacimiento, y de hecho no ocurrirían sin la intervención de los medios. Un ejemplo son las ruedas de prensa, eventos plenamente mediáticos derivados de eventos anteriores.

- Eventos desplazamientos: se refiere a los procesos a través de los que eventos “apariciones" se convierten en "resultados". Básicamente, hay casos en que la dinámica que lleva al medio al lugar del evento (“apariciones”) y la que lleva al evento al lugar del medio ("resultados") se vuelve continua, de forma que toda acción en ese marco (“desplazamiento”) puede devenir evento noticioso: un presidente dando la mano, una celebridad bajando de un avión, la llegada al estadio en autobús de los jugadores de futbol, etc.

A partir de esta clasificación, el gatekeeper debe decidir por qué un evento puede ser noticioso. Y no es tarea tan sencilla, porque puede ser por un personaje, un dato, una fecha, una circunstancia, una imagen impactante...

En realidad, contestando a la segunda pregunta, cuando recibe información múltiple y desestructurada sobre un evento, el gatekeeper debe hacer una selección de las partes de la misma bajo el criterio de más o menos importancia. Esto es común a cualquier discurso y está explicado por teorías clásicas de la información. Mann y Thompson, en una teoría de finales de los 80 (posteriormente mejorada por TABOADA y MANN en 2005 y 2006), establecen unas relaciones jerárquicas entre las categorías informativas de cualquier discurso relacionadas con los efectos sobre el receptor:

- El área del núcleo: unidades informativas más importantes.

- El área del satélite: unidades informativas menos importantes.

- La combinación o relación entre núcleo y satélite.

- Los efectos asociados en el receptor.

Según estos autores, la asignación de la función núcleo o satélite (asignación de importancia) equivale a la asignación de la relación discursiva que mantienen las partes relevantes del discurso. Esa relación siempre debe ser lo más exhaustiva, unívoca y evidente, y puede ser semántica -causal, circunstancial, de elaboración, de

\footnotetext{
${ }^{2}$ Este tipo de análisis discursivo pretendía servir de guía de procesamiento para los robots.
} 
solución y de reafirmación-, o pragmática -motivacional, de antecedente, de justificación y de concesión³.

Ocurre que las unidades de información noticiosa están vinculadas a la vez por relaciones semánticas y pragmáticas, porque al mismo tiempo que se trata de hechos vinculados naturalmente en la realidad, la noticia siempre tiende a hacer explícita la enunciación de ese vínculo. Por ejemplo, si en el discurso de una noticia conectamos el hecho de que "la temperatura entre el PSOE y el PP sube hasta unos niveles que queman", con el hecho de que se produzca "cada vez que en algún escenario político se trata el accidente del Yak-42”, tendremos una relación semántica:

- la temperatura entre PSOE y PP ha subido

- porque

- se ha tratado el accidente del Yak-42;

- pero también tendremos una relación de orden pragmático:

- la temperatura entre PSOE y PP es alta,

- y más cuando

- se ha tratado el accidente del Yak-42.

Estas diferencias sutiles en las relaciones entre unidades pueden esconder intereses económicos, mediáticos o políticos del emisor del proceso, por lo que no son menores. En cualquier caso, Sasha CALHOun (et al., 2005) aplica esta teoría a la noticia y concluye que toda unidad informativa se define por su status de novedad (núcleo) o contexto (satélite). Afirma que una unidad informativa nueva es toda entidad a la que no se ha hecho referencia en el discurso y que es desconocida para el receptor, y que toda unidad informativa vieja es aquella de la que se alimenta la nueva o sin la cual la información nueva sería incomprensible. Además, dice que pueden haber unidades mediadas, que son referenciadas por primera vez en el discurso pero que el receptor hubiera podido inferir por el contexto anterior.

En definitiva, parece claro que el conocimiento o desconocimiento de la información puede ser un criterio de priorización y consecuente selección de la información; es decir, las unidades conocidas aglutinan la novedad y se "oponen” a las no conocidas o contextuales, de forma que las primeras sean más importantes. Pero dado que la información novedosa sería incomprensible sin la información antigua, podemos identificar esa división -y no somos los únicos en hacerlo- con la dicotomía tema/rema (BATES y OstendoRF, 2001, VAN DONZEL y KOOPMANS-VAN Beinum, 1998, Valldubí, 1998, Prince, 1988, Halliday, 1985). De modo que entre los núcleos y satélites de una noticia se establecen relaciones temáticas estructurales. Es más, una vez elegida la novedad principal, el tema del que parte podrá fragmentarse en subtemas relacionados, cada uno de los cuales tendrá subnovedades. Inevitablemente, esto genera una estructura temática jerárquica a partir de la novedad inicial escogida por el periodista:

${ }^{3}$ El siguiente ejemplo puede ayudar a entender la diferencia rápidamente: Relaciones semánticas: "A Ana le gusta Pepe porque se parece a su padre”. Relaciones pragmáticas: "A Ana le gusta Pepe, tal y como ella me dijo". 
"Los temas son cruciales para el entendimiento total de un texto, por ejemplo en el establecimiento de la coherencia global; y funcionan como un control semántico global sobre el entendimiento local en el macronivel. Ciertamente, los temas desempeñan un rol central en un texto. Sin ellos sería imposible entender aquello de lo que globalmente trata el texto. Solamente nos será posible entender los fragmentos locales del texto, y no sus relaciones globales, la jerarquía y la organización” (VAN DIJK, 1990: 60).

Ahora bien, a partir de la tercera pregunta, las unidades de información nueva de cada nivel de la estructura temática necesitan una organización o una marcación que permita su reconocimiento como elementos importantes. GROSz y SIDNER formulan una teoría en 1986 en la que afirman que todo discurso inserto en un proceso de comunicación es la correspondencia entre los elementos físicos del mensaje, las intenciones con las que el emisor crea ese mensaje y las variaciones de atención del receptor cuando se expone a ese proceso. Una total correspondencia representa el nivel máximo de eficacia de la comunicación. La clave perceptiva es por tanto la atención del receptor, dirigida a la información seleccionada "intencionadamente" según unos criterios.

De hecho, la noticia debe conectar la pretensión de privilegiar cierta información con la expectativa que el receptor tiene de la misma (MARTínEz AlBERTOS, 1998). A partir de aquí, un mensaje bien elaborado deberá prevenir los diferentes tipos y niveles de atención en los diferentes tipos y niveles de relevancia de la información. Por ejemplo, es lógico pensar que "si capta la atención, la prosodia contribuye al mismo tiempo a la asimilación del contenido. En este caso, podemos pensar cómo una adecuada acentuación provoca un contraste acústico que dirige el interés del público hacia los datos más relevantes” (RoDERO, 2003: 122).

La atención es por tanto la esencia de la transmisión de todo discurso de la información. Dicho proceso perceptivo se rige por el cambio en la cantidad o calidad del estímulo, ya que la atención es un sistema de alerta que pone en tensión todo el cuerpo, también las cuerdas vocales, por lo que en el caso del habla, la atención se dirigirá hacia los grandes aumentos de tono e intensidad, cambios de voces, pausas, repentinas variaciones sintácticas o semánticas... En un texto, la atención se dirige más a una negrita, un subrayado, un cambio de color...

En resumen, el Discurso Informacional se construye a través de relaciones estructurales atencionales según una jerarquía temática a partir de una novedad eventual. Por tanto, cada unidad de información es importante si es nueva en relación a un tema y si es susceptible de captar la atención. Evidentemente, queda un gran margen de elección para el periodista, que puede enfocar la estructura temática de una noticia en función de la novedad del "sujeto/s” del evento, el “dónde” se produce, el "por qué” o cualquier "circunstancia” que le interese destacar.

Llegados al punto en que el gatekeeper ha elaborado su discurso informacional, el redactor estará en condiciones de convertirlo fielmente en discurso textual. Para ello, precisamos conocer las características lingüísticas del género, y sus posibilidades en cuanto a formato, estilo y lenguaje. 


\subsection{Discurso textual}

De forma general, todo texto se caracteriza por su extensión, la cantidad y longitud de sus partes (párrafos y frases), el tipo de palabras que se utilizan (qué quieren decir, cómo suenan, de cuantas sílabas se componen...), de qué tipo sintáctico son las oraciones, el estilo de redacción (descriptivo, argumentativo, dialogado...), etc. Estos aspectos deberán ser manejados por el redactor teniendo en cuenta:

- el discurso informacional del que parte y en el que se determina el género y se establece la relevancia y la estructura temática del mensaje.

- la estrategia global del medio: como veremos, la escritura de un texto noticioso, a pesar de su evidente rigidez, ofrece grandes posibilidades al redactor para continuar influenciando libremente al receptor a propósito de la transmisión de "novedades temáticas".

Por tanto, este discurso tiene un nivel de estructuración mucho mayor.

En primer lugar, el formato de la noticia se compone de dos unidades flexibles: la locución en plató y el reportaje. El primero es un discurso de 10-30 segundos de un busto que habla a cámara y que representa la parte más sobria e "informativa. El segundo puede tener 4 formas estructurales (MARTínEz AlBeRTOS, 1998: 307-309):

- Reportaje de acontecimiento (Fact story): hecho inicial y más importante + hecho segundo en importancia + hecho tercero + hecho cuarto.

- Reportaje de acción (Action story): se cuenta el incidente inicial + se reanuda el relato con más detalles ambientales + vuelta a la redacción con nuevos datos + nueva redacción + cierre.

- Reportaje de citas o entrevista (Quote story): lead del sumario o introducción global al tema y personaje + cita: palabras textuales + nuevo sumario: ambiental, documental, ilativo, de continuidad... + más citas del personaje + nuevo sumario: narración en tercera persona...

- Reportaje corto: lead del sumario + tie-in + detalles secundarios en orden decreciente.

Teniendo en cuenta que la noticia es una estructura de urgencia y de última hora (siempre en directo), y el reportaje suele ser fruto de un montaje planificado (casi siempre grabado), la imbricación de ambos siempre había sido muy difícil hasta el reciente auge tecnológico. Efectivamente, la actual flexibilidad y versatilidad de los entornos de producción permiten al reportero controlar las diferentes fases de la noticia y tomar decisiones congruentes con su papel estratégico de emisor. En el rango de estas decisiones se sitúan las unidades narrativas del discurso. Así por ejemplo, en el caso de que la unidad noticia sea acompañada por un reportaje de acontecimientos, debemos ser conscientes de que la misma estructura global de la unidad noticia sería reproducida a menor escala en el interior del reportaje: arranque con hecho principal, distribución de hechos secundarios y subrayado final del hecho noticioso principal. Igualmente, la distribución en la exposición de hechos secundarios sigue una cadencia rítmica que se corresponde con una graduación de los puntos de interés. Por su parte, la enunciación en plató es un discurso lineal que se corresponde con el lead del periodismo escrito: contesta al "qué, quién, cuando, cómo y por qué” de forma gradual y mediante frases enunciativas y subordinadas. 
En segundo lugar, el discurso textual podrá adoptar tres tipos de estilo que determinarán el margen de formalidad, rigurosidad y emotividad que el género permite (CEBRián HERREROS, 1992):

- Estilo Informativo Directo: el presentador es un mero transmisor de la información, por lo que suele tener una actitud neutral, de urgencia y de veracidad, reduciendo la expresividad a las emociones más básicas: noticias urgentes, neutras (política o economía), alegres (fiestas, deportes), tristes (sucesos) o distendidas (cultura o ciencia).

- Estilo Informativo Coloquial: el presentador es un transmisor participante de la noticia en cuanto mantiene el interés y facilita la comprensión de la noticia como si fuera una conversación informal e interpersonal. Por eso, el estilo locutivo es espontáneo y unidireccional.

- Estilo Informativo Sugestivo: el presentador participa plenamente de la noticia, apelando y emocionando al espectador a propósito de las informaciones.

Estos estilos no son excluyentes entre ellos. Más bien diríamos que el estilo de un texto noticia será más o menos directo, y más o menos coloquial y sugestivo, en función de los objetivos comunicativos del canal (el rigor, el entretenimiento o el nivel sociocultural de sus receptores) y el tema general de la información: es muy tentador situar los temas Economía y Política en el extremo más formal del estilo y los temas Deportes, y Ciencia y Cultura en el opuesto.

En tercer lugar, a pesar de que la elección del formato y del grado de estilo ya determina un tipo de organización textual, sintáctica y léxica, es decir, un tipo de párrafos, frases y palabras; siempre hay un momento en que el redactor se sienta delante del teclado y elige las palabras concretas para expresar las unidades informativas. Nos referimos ahora a la escritura periodística (CHARADEAU, 1984: 6) o el lenguaje periodístico, caracterizado por los siguientes rasgos típicos o "notas ideales" (MARTínez AlBertos, 1998):

1. Corrección: es un lenguaje no-literal próximo a la lengua coloquial culta.

2. Concisión: predominio de sintagmas nominales en frases cortas (30-36 sílabas/frase, 15-17 palabras/frase).

3. Claridad: verbos en forma activa y en indicativo ${ }^{4}$.

4. Especificidad: como decíamos, cada tema determinará tipos concretos de palabras:

a) Economía: datos, porcentajes y cantidades en general.

b) Política: nombres de protagonistas, verbos de acción y fechas.

c) Urgente: cuándo, cómo y por qué.

d) Sucesos: quién y cómo.

e) Internacional: países, gentilicios, etc

${ }^{4}$ El mismo autor añade más adelante en su obra que el periodista debe utilizar palabras llanas y simples, en giros directos. 
f) Cultura/ Sanidad/ deportes/ tránsito/ trabajo/ educación/ medios/ ciencia: vocabulario específico de los diferentes campos, pero en general: lenguaje más coloquial o informal (de estilo distendido como veremos más abajo) ${ }^{5}$.

5. Intertextualidad: ¿cómo es un lenguaje que conjuga la lengua culta y cotidiana, escrita y oral, formal e informal? En general, es fundamental que se escriba como se habla, es decir que se dicte oralmente el texto para ser escrito, porque después se leerá fingiendo que no se lee.

En tercer lugar, sabemos que el discurso textual de la noticia en televisión se caracteriza estructuralmente por las características del género informativo, que según CeBrián HeRreros puede ser de tres tipos (1983: 15):

- Género Informativo Testimonial-expresivo: tiene el propósito de argumentar (editorial), interpretar (comentario), analizar (crítica) o mostrar una actitud (crónica) hacia una información.

- Género Informativo Dialógico: trata de indagar, consultar, cooperar o participar, y polemizar a propósito de una información, dando lugar a géneros como la entrevista, la encuesta, la rueda de prensa, los interrogatorios o los debates.

- Género Informativo Referencial: en este caso, el emisor pretende "exponer acontecimientos externos, hechos informativos comprobables, opiniones contrastables” (1993: 39), pudiendo adoptar diferentes actitudes, y dando lugar a los siguientes subgéneros:

- Actitud de fidelidad escueta: la noticia.

- Actitud profundizadora: el reportaje.

- Actitud recopiladora y ampliadora: el informe periodístico.

- Actitud notarial: el documental.

- Actitud dramática: el docudrama.

La noticia, de género referencial, se caracteriza, en sus diferentes fases, por un arranque y una entrada o lead, un desarrollo y un cierre. El arranque suele ser una frase larga donde se concentra la gran novedad de la información, y a continuación el lead trata de contestar con las palabras precisas y sucintamente a las 5 preguntas básicas del periodismo. A continuación, el "desarrollo" de la noticia supone una vuelta a los datos más importantes del inicio, que serán diseminados periódicamente con la correspondiente aportación de detalles para cada uno. Por último, el cierre no aporta información nueva, sino que trata de condensar y sobresaltar la información más importante en dos o tres frases.

Como vemos, la noticia en televisión pertenece al género informativo referencial porque persigue referenciar una unidad informativa (novedosa) a partir de la cual se construye la estructura temática y atencional de la noticia. Por eso, dos referencias

${ }^{5}$ Esta propuesta resumida de tipología de palabras-clave temáticas está basada en el Inventario cerrado de 1000 palabras que se definió en nuestra tesina (MAS MANCHón, 2006) en el marco del proyecto CLAIS, financiado por el CAC (Consell de l'Audiovisual de Catalunya), que se puede consultar en el Archivo del CAC o en el Laicom (Seminario 1, Edifici I, UAB). 
supondrán dos estructuras y, por tanto, dos noticias, y así sucesivamente. Ahora bien, en la época de los género híbridos, las noticias adoptan en ocasiones marcas del género dialógico (cuando hay cierta interacción entre los presentadores) y testimonial (el presentador se implica en la información)

\subsection{Discurso vocal}

¿En qué consiste “leer” como si no se leyera? ¿Cómo se lee dando la impresión de que se está improvisando? HiLls (1981: 55, citado en MARTínEz AlBERTOS, 1998) se limita a decir que la oralización informativa en radio o televisión, es decir, "su entonación, inflexión, fraseo y pausas, deben ser los de una conversación natural, pero sin titubeos o equivocaciones”. Por fraseo se entiende la sucesión de lo que Hills llama "grupos-concepto" en la locución informativa, que es la combinación de palabras y su organización en conjuntos, acopladas en estructuras rítmicas y con pausas expresivas intercaladas, con timbres preferentemente altos y una dicción que asegure la claridad de las vocales. El presentador maneja (articula) su voz para comunicar de la mejor forma el contenido del texto que tiene delante. Lo cierto es que la estructura discursiva, informacional y textual, se reproducen en el discurso vocal mediante variaciones de tono, ritmo e intensidad. Es más, tal y como corresponde a un discurso integral-estructural en niveles-, desde la primera decisión del gatekeeper y en cada una de las tomadas por el redactor, se ha tenido en cuenta el discurso vocal.

Por tanto, ¿cuáles son esas unidades de oralización de la información noticiosa? ¿Qué formas prosódicas típicas de la locución informativa sirven a los objetivos comunicativos del emisor? ¿Qué tipo de manejo discursivo y estratégico nos permiten los parámetros articulatorios?

En primer lugar, las unidades de oralización no son sino fragmentos de locución entre pausas, que serán expresados de forma ideal si se le da un sentido entonativo, rítmico y articulatorio. Así, definimos la unidad entonativa como el conjunto de "compases" que conforman una melodía propia entre pequeños silencios para respirar $^{6}$. Puede componerse de 1, 2 ó 3 grupos fónicos, que son pequeños fragmentos tonales limitados por respiraciones más cortas gracias a las cuales se articulan los fonemas. La unidad entonativa suele estar marcada con signos de puntuación (comas, puntos y comas o puntos) y consiste en un contorno melódico reconocible. Pero esa unidad entonativa también es rítmica, ya que define una coherencia rítmica que tiende a asociar el ritmo con los eventos de la unidad entonativa mediante formas rítmicas asociadas a las formas tonales: la duración de los grupos fónicos, el alargamiento de las sílabas acentuales y el ritmo de aparición de los acentos y de sus diferentes alturas, o la duración de los diferentes tipos de pausas. En todo caso, la generación de tono y el mayor o menor ritmo que se imprime al habla están directamente relacionados con la cantidad de aire del que

\footnotetext{
6 “La porción mínima de discurso con forma musical determinada siendo al propio tiempo una parte por sí misma significativa dentro del sentido total de la oración” (NAVARRO ToMÁs, 1974: 38).
} 
dispone el presentador, por lo que la unidad prosódica se define al fin por el contorno melódico, determinado por un ritmo y ciertas duraciones de las sílabas involucradas, las pequeñas pausas entre grupos fónicos y las grandes respiraciones antes y después de dicha unidad.

En segundo lugar, en cada unidad prosódica se producen variaciones prosódicas combinadas con la estructura textual. Estos eventos son llamados formas prosódicas y sirven a una función discursiva (MAS MANCHÓN, 2008):

a) Picos tonales: aumento del tono en un rango de 1 ó 2 de sílabas. Es la forma básica en que se presenta el énfasis de la información de la noticia, por lo que su aparición y organización representa los cimientos del modelo que se ha diseñado.

b) Prominencia: aumento del tono y la intensidad, y mayor duración de las sílabas de las palabras-clave, que son las representantes del núcleo discursivo de la noticia.

c) Plateau: fragmento de locución sin picos tonales ni prominencias, y, por tanto, sin información importante.

d) Downtrend: es la relación descendente de al menos tres picos tonales entre pausas, por lo que implica cierta organización de la información importante. Se produce cuando el gasto de aire es muy grande, normalmente a principio de noticia.

e) Reset: pico acentual que rompe la tendencia a la baja de un downtrend. Se caracteriza por los siguientes principios:

e.1) El último pico tonal de un downtrend tiene que ser menor que el primer pico del siguiente.

e.2) El primer pico tonal del segundo dowtrend tiene que ser menor que el primer pico tonal del primer downtrend (BAQUÉ y EsTRUCH, 2003: 147).

Así, enlazando con lo anterior, si el reset va acompañado por la pausa definida, la frontera del "grupo entonativo" quedará establecida. Además, el grado en que se manifiesta también determina el grado de importancia, emoción y urgencia de la información.

f) Coda: rasgos prosódicos de final de melodía: anticadencia entonativa, caídas de intensidad y alargamientos de sílaba (VAISsière, 1991), que serán más acentuadas conforme más expresivo sea el estilo de locución.

Pero no olvidemos, en tercer lugar, que la forma en que se configuran estas unidades pragmáticas y sus formas prosódicas es a través de la articulación del tono, ritmo e intensidad. El tono se refiere a la sonoridad de la voz, que es máxima en el caso de las vocales, por lo que se toma la sílaba como unidad mínima tonal. Esas variaciones de tono son las que dan lugar a la entonación de una locución representadas por una curva melódica. Por su parte, el ritmo se refiere directamente a la cronología de los datos de tono y la duración de cualquier fenómeno prosódico que se defina por este parámetro: prominencias, tipos de pausas, coda, etc. Y la intensidad tiene que ver directamente con la cantidad de aire de que se dispone, y por tanto también con la fuerza articulatoria, el gasto de energía en relación al tono y el ritmo, y las respiraciones.

Un manejo experto de estos parámetros permitirá al presentador tener el control estructural de lo que está contando y un margen de libertad para sus propios 
objetivos comunicativos, tales como su integración en el starsystem de los presentadores en particular y de la televisión en general a partir de su estilo personal.

\section{El modelo}

Hemos visto que la noticia se compone de tres tipos de discursos como 3 niveles estructurales del mensaje, y compuestos cada uno de 3 subniveles. La conexión estructural hace que tales subniveles estén conectados entre sí.

Gráfico 1. Modelo Superestructural de la Noticia. Elaboración Propia

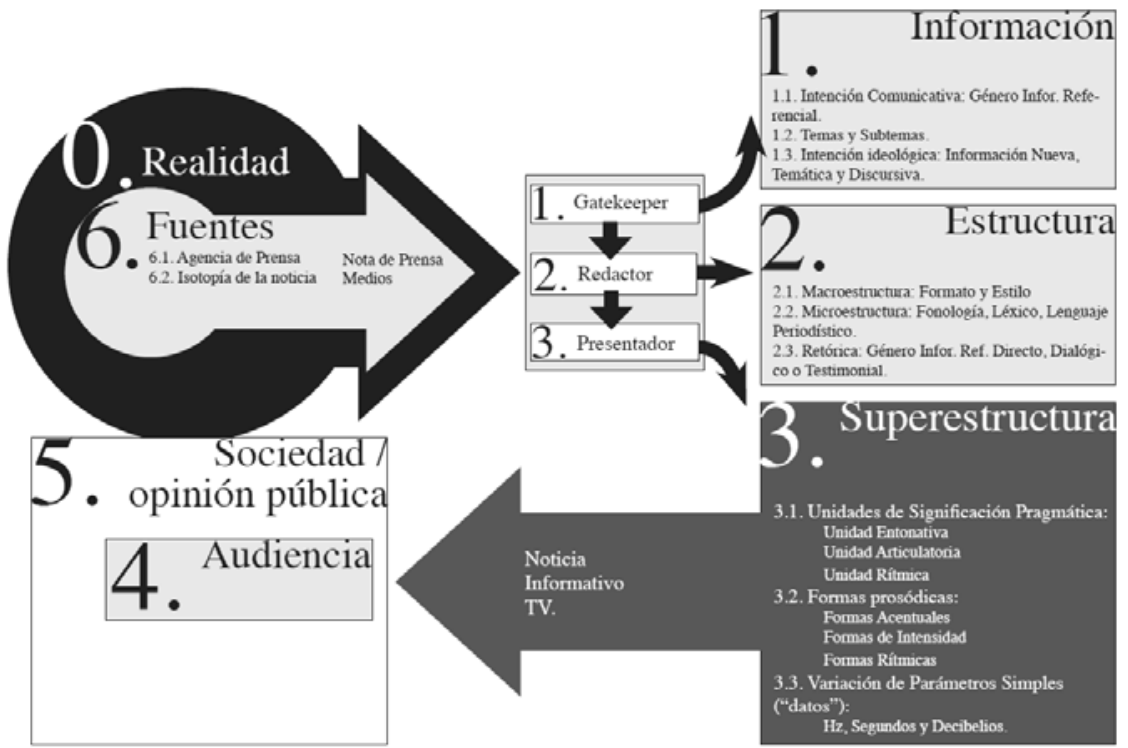

\subsection{Aplicación del modelo}

Este es el proceso de transmisión y procesamiento de la noticia?:

0. Realidad: es una explosión de aconteceres que no cesa. Es un Big Bang que expande eventos por todos los lados, algunos de los cuales son noticiosos y efectivamente se convierten en noticia si un medio así lo considera a través de su "gatekeeper". Parte de esos eventos que salen disparados en todas direcciones se han desprendido de eventos ya convertidos en noticia, en cuyo caso son de por sí eventos noticiosos y no necesitan pasar por el gatekeeper -directamente pasan a manos del "redactor".

1. Gatekeeper:

1.1. Intención comunicativa: sin la intención de transmitir algo no hay proceso de comunicación y por tanto no hay emisor. Se trata de decidir cuál es la parte informativa más importante del evento, en virtud de la cual se puede convertir en noticia para su medio.

\subsection{Estructura temática: toda noticia se define por un tema noticioso elegido y}

\footnotetext{
${ }^{7}$ La subsiguiente explicación esquemática sigue el orden lógico-numérico del esquema. Reconocemos en ella los 3 subniveles de los 3 discursos que acabamos de ver.
} 
unos subtemas afines que contribuyen a encuadrarlo a través de relaciones temáticas, jerárquicas y solidarias entre ellas. Esta imbricación de las informaciones según el criterio temático es fundamental para que el redactor tenga después los mecanismos de cohesión y coherencia necesarios para entender y por tanto explicar en palabras lo acontecido.

1.3. Intención ideológica: el gatekeeper, en representación del medio, es parte interesada del proceso ya que elige más o menos arbitrariamente:

1.3.1. Unidades de novedad: elegir la novedad más importante del día.

1.3.2. Unidades de tema: establecer la agenda temática de los medios.

1.3.3. Unidades discursivas: posicionarse sobre los temas mediante las relaciones discursivas que conectan las unidades temáticas.

2. Redactor: recibe un conjunto de informaciones relacionadas que explican (describen) un evento noticioso, por lo que actúa como si todo lo que supiera del evento fuera la información que le llega.

2.1. Macroestructura: las informaciones semi-redactadas (semi-estructuradas) en forma jerárquica se organizan en una estructura general: un formato y un estilo.

2.2. Microestructura: el redactor toma decisiones en el ámbito fonológico, léxico y lingüístico, para transformar la macroestructura de unidades informativas en un texto lineal.

2.3. Retórica: el redactor aderezará el tipo de texto escrito en función del "tono" o carácter que le quiera dar a la transmisión. Este puede ser directo (neutral), testimonial (participativo) o dialógico (informal).

3. Presentador: debe descifrar el código superestructural (oral y expresivo) contenido en el texto noticioso:

3.1. Unidad pragmática: este presentador reconoce una división sintáctica y semántica que predetermina un tipo de enunciación prosódica y facilita el procesamiento global del discurso, ya que tiene en cuenta la melodía de sus partes (unidad entonativa), las respiraciones y la fuerza articulatoria (unidad articulatoria) y el ritmo de habla (unidad rítmica).

3.2. Formas expresivas orales: implícitas en los niveles estructurales del discurso noticia, se generan estratégicamente formas acentuales, rítmicas y de intensidad.

3.3. Variaciones de parámetros simples: el presentador maneja la vibración de sus cuerdas vocales (el tono), la velocidad de articulación (el ritmo) y la cantidad de aire utilizado por unidad de tiempo (la intensidad) para generar esas formas expresivas y esas unidades, y tener aún un grado de libertad expresiva.

4. Receptores:

4.1. Atención: mayor cuanta más variación y/o sincronía de cualquier tipo de estímulo.

4.2. Representación mental del significado y referente al que remite esa palabra.

4.3. Comprensión: opinión social o pública, positiva o negativa, duradera o pasajera, acerca de la información noticiosa. La noticia habrá pasado a ser el evento y estará construyendo la realidad. 
5. Sociedad/Opinión Pública: es la “realidad” intervenida para siempre por la noticia.

\subsection{Análisis}

Fruto del proceso de configuración discursiva de la noticia, este mensaje se compone de "información”, “estructura (textual)” y "superestructura (oral)”, que son los tres niveles estructurales de la noticia en TV, cada uno de los cuales está en función dependiente del resto, porque el mensaje sólo existe como superestructura integrada en el momento de su enunciación en directo y ante las cámaras:

1. Información:

a) Rasgos Formales 1: Intención Comunicativa.

b) Rasgos Formales 2: Temas y Subtemas.

c) Rasgos Formales 3: Intención Ideológica.

2. Estructura:

a) Rasgos textuales 1: Macroestructura.

b) Rasgos textuales 2: Microestructura

c) Rasgos textuales 3: Retórica.

3. Superestructura:

a) Rasgos Vocales 1: Unidades de Significación Pragmática.

b) Rasgos Vocales 2: Formas Prosódicas.

c) Rasgos Vocales 3: Variación de Parámetros Simples.

Como se ve en el esquema, los criterios de configuración de cada nivel se han convertido en rasgos de complejidad en la elaboración (codificación) de la noticia. Por tanto, decimos que la noticia en televisión se compone de rasgos formales, textuales y vocales, integrados en tres fases de codificación y correspondidos con el proceso de decodificación o procesamiento.

A partir de aquí, nuestro modelo aspira a mostrar cómo los rasgos vocales de la noticia dependen de los rasgos formales y textuales de los que parte; o, en otras palabras, este modelo evidencia la parte de variación de los rasgos vocales explicada por los rasgos formales y textuales de la noticia.

Como ejemplo, a continuación vamos a analizar la estructura discursiva de la noticia emitida por el canal Cuatro el 2 de julio de 2009 y locutada por Iñaki Gabilondo. Marcamos en negrita las palabras resaltadas y mediante barras las pausas (/, //, ///, según sean más o menos largas), que se reconocen en una primera escucha (sin análisis fonético).

Regresamos a España. // La Cátedra de Estudios Iberoamericanos Jesús de Polanco / ha analizado en Santander la crisis global.//

En el encuentro participan el ex presidente Felipe González, catedráticos como Antonio

Rovira, / y periodistas, como Joaquín Estefanía.//

Los debates han abordado la gran depresión del 29 y su comparación con la crisis actual./

También su posible incidencia en la literatura, el cine, la política o la economía./// 
Nivel 1. Rasgos formales: con la información noticiosa de un evento en sus manos, el gatekeeper define los rasgos formales en tres subniveles:

1. Intención Comunicativa ("Género Informativo Referencial”): el evento noticioso originario -la "explosión” de la "realidad- es "la crisis económica mundial", cuyo tratamiento como noticia ha provocado a su vez una espiral de noticias derivadas de la "opinión de expertos, políticos o historiadores con experiencia para prever las acciones en base a situaciones pasadas similares”. En este caso, la noticia inserta en el informativo de Cuatro tiene la intención referencial de informar sobre los protagonistas de la Cátedra de Estudios Iberoamericanos y su opinión como expertos acerca de la crisis económica mundial.

2. Temas y Subtemas: en la noticia, aparece la siguiente jerarquía temática:

- La Cátedra de Estudios Iberoamericanos ha organizado un debate sobre la crisis económica,

- esa cátedra lleva el nombre y es en honor a Jesús de Polanco,

- en ella han participado expertos como Felipe González, Antonio Rovira y Joaquín Estefanía,

- quienes la comparan con la crisis del 29

- y afirman que es una crisis global.

3. Intención Ideológica: bajo el tema principal de que "la crisis económica ha sido tratado en un importante foro" y la "novedad" de que "lo organiza el Grupo Prisa y han participado grandes personalidades", se pretende dar notoriedad al Grupo Prisa y a la propia Cuatro. Esa intención ideológica está totalmente integrada y compatibilizada con la intención informativa y la noticiabilidad general, ya que se conjugan las "importantes" conclusiones de la cátedra -"se trata de una crisis 'global' parecida a la del 29”- con los intereses del Grupo Prisa ${ }^{8}$ notoriedad e imagen pública- mediante dos tipos de relaciones "discursivas":

a) Contexto semántico: en efecto, el hecho de que "el Grupo Prisa [haya] analiza[do] la crisis global" tiene relación con: "quien” la ha "analizado", en "qué” consiste esa cátedra, "cómo" la han analizado (comparándola con la del "29") y los "resultados" obtenidos (es una "crisis global”).

b) Contexto pragmático: para dar notoriedad a esa Cátedra y al trabajo que realiza, las relaciones semánticas son imbricadas mediante relaciones discursivas enfatizadas y coherentes con la "importancia" del evento: se destaca el "encuentro", la participación del "ex presidente” y los "catedráticos”, su "incidencia"...

Nivel 2. Rasgos textuales: condicionado por los rasgos formales que el gatekeeper ha dado a la información noticiosa, el redactor escribe el texto o guión de la noticia haciendo uso de rasgos textuales generados en tres subniveles:

1. Macroestructura: se utiliza un estilo directo y con una única locución en plató para dar el sentido de neutralidad, objetividad, autenticidad y rigurosidad.

2. Microestructura: estos son los rasgos textuales en el nivel micro:

${ }^{8}$ Tampoco es casual que sus protagonistas sean de izquierdas y afines al PSOE, empezando por Felipe González. 
a) Fonológico: palabras que suenan bien ("Estudios Iberoamericano", "Santander"), que están de moda y por tanto tienen un gran valor "representacional” (“gran depresión del 29", “crisis global”...), y que dan ritmo a la locución (“[...], como [...]”, "También”, "el cine, la política o la economía”).

b) Léxico:

b.1) Palabras de información nueva: "Santander", "Polanco"10, "Felipe González”11, “Antonio Rovira”, "Joaquín Estefanía”, “el cine, la política o la economía”.

b.2) Palabras de información temática: “crisis global”, "gran depresión del 29", “economía”.

b.3) Palabras de información discursiva: “También”, “encuentro”, "Estudios Iberoamericanos"12, etc.

c) Periodístico (lenguaje): se combinan palabras técnicas (“crisis global”, “debate”, "gran depresión”) y nombres completos por importantes (“Antonio Rovira”, "Joaquín Estefanía”).

3. Retórica: se trata sin duda de un estilo "referencial directo", en que el presentador se presenta como mero transmisor que abre la ventana del mundo al telespectador. Este tipo de retórica es fundamental en la noticia pues la novedad está contenida en la importancia y relevancia "per sé” del evento. Evidentemente, este es un típico evento de "apariciones", que pasaría desapercibido sin la presencia de los medios y que por tanto cambia radicalmente con la intervención de éstos. La "importancia” del evento viene dada principalmente por el hecho de "ocurrir" (ante las cámaras), más que por lo que en realidad ocurre in situ. Al convertirlo en noticia con todos los honores (como si fuera un evento “explosión"” ${ }^{13}$, enunciación y evento se retroalimentan y se dan importancia mutua; de forma que el Grupo Prisa adquiere relevancia pública. Es está la retórica optimizada de toda noticia corporativa ${ }^{14}$.

Nivel 3: Superestructura: en un tercer nivel estructural de la noticia, los rasgos vocales están contenidos en unidades prosódicas de significación pragmática de la noticia, que, en la mayoría de los casos, tienen correspondencia con las unidades

${ }^{9} \mathrm{Al}$ repetir dos veces la estructura: “catedráticos ‘como’...” y “periodistas, como’...”; se están destacando “qué” catedráticos y periodistas, y se está imprimiendo ritmo a la locución y al discurso, dándole autoridad y rigurosidad como veremos en su estructura retórica.

${ }^{10}$ El “quien” del periodismo es el elemento más importante. Lo que hace ese “quién”, o el hecho de que sea "él/ella” quien lo haga, es la información novedosa en este caso.

${ }^{11}$ No es que sea alguien novedoso o no conocido, sino que la novedad es su participación en el foro representada por la enunciación de su nombre en esta noticia.

12 No hace falta enunciar cada vez todo el nombre de la Cátedra, y menos aún cuando no aporta información relevante a la cuestión (nada tiene que ver ese encuentro con Sudamérica); es por eso que el hecho de insistir en enunciar el nombre completo sirve a una función discursiva: vehicular la exaltación del nombre "Jesús de Polanco", que es donde reside la tematicidad y riqueza informativa de esta noticia.

${ }^{13}$ Lo que conllevaría que todos los medios se ocuparan de ello, cosa que obviamente no ocurre.

${ }^{14}$ Aquella que conjuga la intención informativa e ideológica de la función comunicativa general de la noticia. 
semánticas del texto (las frases) y las unidades articulatorias, entonativas y rítmicas. A continuación presentamos las unidades en las que se divide el "texto oral noticia" y los rasgos vocales que desencadenan. Según el método de análisis fonético prosódico que hemos adoptado en nuestra línea de investigación (Mas Manchón, 2008, 2009), analizaremos picos de tono e intensidad, medidos en porcentajes de variación, duración de sílabas y cantidad de sílabas por unidad de tiempo:

1. "La Cátedra de Estudios Iberoamericanos Jesús de Polanco / ha analizado en Santander la crisis global.//":

1.1. Movimientos tonales: inicio enfático (39\%) y downtrend enfático (42\% de caída entre picos y reset de -36\% respecto del primer pico).

1.2. Prominencias: palabra-clave "estudios", con picos de $280 \%$ de tono, 3.6\% de intensidad y 0.147 de duración de alargamiento, palabra-clave "Jesús (Polanco)" (70\% de pico de tono, 5\% de intensidad y 0.176 de duración), y palabra-clave "global" (36\%, 3\% y 0.206).

1.3. Ritmo: muy alto (media de 482 sílabas/minuto) y ligeramente descendente (de 0.11 a 0.13 segundos/sílaba).

1.4. Coda: enfática, con una caída de $-35 \%$ en el tono, $-2.5 \%$ de intensidad, y un alargamiento de 0.206 seg.

2. "En el encuentro participan el ex presidente Felipe González, catedráticos como Antonio Rovira, / y periodistas, como Joaquín Estefanía.//":

2.1. Movimientos tonales: inicio normal (27\%), valle acentuado (44\%), downtrend enfático, con un 34\% de caída entre picos, y reset un 32\% menor al primer pico.

2.2. Prominencias: palabra-clave "presidente" (pico de $83 \%$ de tono y $15 \%$ de intensidad, y 0.155 de alargamiento), palabra-clave "catedráticos" (117\%, $2.5 \%$ y 0.200 ), palabra-clave "Rovira" (75\%, 8\% y 0.200), y palabra-clave “Joaquín (Estefanía)” (50\%, 3.75\% y 0.249).

2.3. Ritmo: alto (media de 428 sílabas/minuto) y descendente (tres grupos fónicos de 0.12, 0.14 y 0.19 segundos/sílaba).

2.4. Coda: enfática, con una caída de $-51 \%$ en el tono, $-10 \%$ de intensidad, y un alargamiento de 0.225 seg.

3. "Los debates han abordado la gran depresión del 29 y su comparación con la crisis actual./ También su posible incidencia en la literatura, el cine, la política o la economía.///”:

3.1. Movimientos tonales: inicio enfático (39\%), downtrend poco enfático, con un 23\% de caída entre picos, y reset un 20\% menor al primer pico.

3.2. Prominencias: palabra-clave "debates" (pico de $80 \%$ de tono, $1 \%$ de intensidad y 0.202 de alargamiento), palabra-clave "gran depresión [del 29]" (pico de $91 \%$ de tono, $14 \%$ de intensidad y 0.250 de alargamiento), y palabraclave "también" (pico de $89 \%$ de tono, 4\% de intensidad y 0.360 de alargamiento).

3.3. Ritmo: alto (media de 426 sílabas/minuto) e irregular (tres grupos fónicos de $0.13,0.14$ y 0.12 segundos/sílaba)

3.4. Coda: enfática, con una caída de -36\% en el tono, $-2.5 \%$ de intensidad, y un alargamiento de 0.214 seg. 


\subsection{Resultados}

Esta noticia tiene una eficaz estructura discursiva integral. Porque en función de su intención comunicativa general (informativa e ideológica), se le ha dado una organización temática y una expresión léxica y vocal (semántica y fonológica) perfectamente coherentes y cohesionadas.

\section{Discusión}

Este es un modelo de la eficacia de la noticia. Contribuye a saber cómo elaborar una noticia en televisión para comunicar de la forma más eficiente.

Como hemos visto, el modelo se apoya sobre el tipo de género informativo referencial, lo cual podría parecer expeditivo en tiempos de géneros híbridos y manipulación informativa. De hecho, en la actualidad, un mismo telespectador puede aprehender una realidad diferente según asista a informativos de corrientes políticas opuestas. Teniendo esto en cuenta, ¿cómo se puede modelar un discurso informativo que transmite realidades opuestas de un mismo evento? Creemos que nuestro modelo responde a esta pregunta, porque contempla una parte informativa y una parte retórica de la función comunicativa del discurso noticia. Esto se ha visto claramente en el ejemplo de la noticia de Cuatro, el cual vehiculaba información libre o interesada en forma de noticia referencial y rigurosa y de encaje estructural perfecto. Si una ola de frío ha dejado la mayor nevada en Barcelona de la historia, y se decide que la noticia (la "referencia") no es lo "inusual del fenómeno meteorológico" sino "la no previsión y gestión política”, será porque muy probablemente el medio de comunicación tiene el objetivo de criticar al gobierno -intención ideológica. En ese caso, se trataría de "otra” noticia y el género referencial prevalecería.

Por tanto, los límites permitidos de la manipulación de la noticia son la medida en que los criterios ideológicos intervienen en la elección del elemento de la realidad y se expresan a continuación en los subniveles 3 de la estructura: ideología de la información, retórica del texto y expresividad libre de la locución. Esto no quiere decir que toda noticia puede manipular a su antojo sin que nuestro modelo lo detecte. Muy al contrario, nuestro modelo define los niveles en que se puede expresar la parte informativa y la retórica, y el nivel de integración estructural de cada una. La noticia de Cuatro presentaba una estructura integral, pero en otro lugar (MAs Manchón, 2010b), hemos podido comprobar que una noticia corporativa de Canal 9 resultaba en un discurso adulterado, contraproducente y de dudoso género.

Este modelo se encarga de indicar la estructura flexible ${ }^{15}$ que una noticia debe adoptar a partir de los objetivos exactos y conocidos del emisor, sean informativos o ideológicos, dejando espacio a factores personales.

${ }^{15}$ Por ejemplo, en un estudio reciente hemos definido los patrones estructurales generales de la intención ideológica del discurso formal (MAS MANCHÓN, 2010a): las palabras-clave de novedad son modelizables por el gran énfasis prosódico, las palabras-clave temáticas por su morfología y las palabras-clave discursivas por su emplazamiento al principio de la unidad entonativa. 


\section{Conclusiones}

En este artículo hemos presentado un modelo de la dimensión pragmática de la noticia en televisión, consistente en principios que culminan la estructuración del tipo de discurso. En esta línea de investigación, se ha probado que la noticia es un discurso:

1. Estructural e integral: cada nivel discursivo del mensaje contribuye a la expresión superestructural de la dimensión pragmática. El uso de ciertas palabras y no otras o el estilo de redacción no sólo dependen de aspectos sintácticos y semánticos, sino también de cómo "suenan" oralmente. Por tanto, la dimensión pragmática se explica mediante un modelo superestructural intervenido por los niveles micro y macroestructurales.

2. Jerárquico: mientras la superestructura definida caracteriza a todas las noticias, la semántica las tipifica según su tema y el léxico las individualiza. Por lo tanto, este modelo discursivo de la noticia propone niveles estructurales solidarios.

3. Procesal: como se ha visto, la noticia es una ente abstracto que está en constante elaboración y procesamiento. En consecuencia, el gatekeeper recibe estímulos noticiosos constantes en función de las noticias emitidas por los diferentes medios, de forma que la estructura de la noticia es parte de una red de estructuras: todo el día se están elaborando y procesando noticias y éstas se retroalimentan unas a otras en la creación de eventos noticiosos, producción de noticias, y, en fin, establecimiento de una opinión pública.

Por lo tanto, en general concluimos que el patrón formal y textual de la noticia determina una enunciación oral caracterizada por grandes aseveracionesafirmaciones. Hasta el momento, nadie había dado una explicación discursiva, estructural e integral de esos rasgos prosódicos. Ahora sabemos que el proceso viene dado por 3 tipos de procesamiento, producción y discurso, expresados en tres subniveles:

1. Subnivel 1: Intención Comunicativa (Discurso Formal) --> Macroestructura (Discurso Textual) --> Unidades de Significación Pragmática (Discurso Vocal).

2. Subnivel 2: Temática (Discurso Formal) --> Microestructura (Discurso Textual) --> Formas prosódicas (Discurso Vocal).

3. Subnivel 3: Intención Ideológica (Discurso Formal) --> Retórica (Discurso Textual) --> Variación de parámetros simples (Discurso Vocal).

Por lo tanto, la intención comunicativa del género informativo no da elección y predetermina una macroestructura y un tipo de organización oral general en unidades pragmáticas. La temática definida, bajo cierto arbitrio, se define en el texto de forma flexible según una microestructura y se expresa oralmente mediante formas prosódicas. Y la intención ideológica que el periodista, canal o grupo mediático pudieran tener, se expresa retóricamente en el texto y libremente mediante la variación vocal de tono, ritmo e intensidad dentro de los rangos que las formas y unidades prosódicas le permiten. 


\section{Referencias bibliográficas}

BAQUÉ, Lorraine y ESTRUCH, Mónica (2003): “Modelo de Aix-en-Provence”. En PRIETO, Pilar (Coord.): Teorías de la entonación. Barcelona, Ariel.

BATES, Rebecca y OSTENDORF, Mari (2001): "Modeling Pronunciation Variation in Conversational Speech using Syntax and Discourse”. ISCA Tutorial and Research Workshop on Prosody in Speech Recognition and Understanding, October 22-24. URL: http://www.isca-speech.org/archive, [última consulta el 12 de marzo de 2008]

BERTALANFFY, Ludwig von (1968, 1986): Teoría General de Sistemas. México, Fondo de Cultura Económica.

CALHOUN, Sasha et al. (2005): “A Framework for Annotating Information Structure in Discourse". URL:

http://www.cstr.ed.ac.uk/downloads/publications/2005/pieinsky05.pdf

CEBRIÁN HERREROS, Mariano (1983): Fundamentos de la teoría y técnica de la información audiovisual. Madrid, Mezquita.

- (1992): Géneros informativos audiovisuales. Madrid, Ciencia.

GOMIS, Lorenzo (1991): Teoría del periodismo: cómo se forma el presente. Barcelona. Paidós.

GROSZ, Barbara J. y SIDNER, Candace L. (1986): “Attention, Intentions, and the Structure of Discourse. Computational Linguistics”, 12:3.

HALLIDAY, Michael Alexander K. (1985): An Introduction to Functional Grammar. London, Arnold.

MARTÍNEZ ALBERTOS, José Luis (1998): Curso General de redacción periodística. Madrid, Paraninfo.

MAS MANCHÓN, Lluís (2006): “Creación de un inventario de palabras-clave para la identificación temática de noticias de televisión en catalán”. Tesina dirigida por Àngel Rodríguez Bravo y presentada en el Departamento de Comunicación Audiovisual y Publicidad, UAB. En el marco del proyecto CLAIS. RODRÍGUEZ BRAVO, Á. et al. (2005). "Estudi sobre "Noves aplicacions que podrien desenvolupar-se per a l'evolució i millora del sistema d'enregistrament automàtic, catalogacio i anàlisi del CAC”. Entidad Financiadora: Consell de l'Audiovisual de Catalunya (7848164691). DURACIÓN: 13/10/04 - 31/12/05. En Archivo del CAC o Laicom (Seminario 1, Edifi I, UAB).

- (2008): “Testeo de tres procedimientos de obtención de pitch para la modelización prosódica del discurso noticia”. Phonica: UB. Online, URL: http://www.publicacions.ub.es/revistes/phoni ca4/, [última consulta el 15 de septiembre de 2010]

- (2009): "Formas entonativas en las fases del Discurso Noticia". Actas XXXII Congresso Brasileiro de Ciências da Comunicação. Curitiba, (PR, Brasil), del 4 al 7 de septiembre, 2009. URL:

http://www.intercom.org.br/papers/nacionais/2009/lista_area_DT1-TE.htm [última consulta el 12 de julio de 2010]

- (2010a): "Palabras-clave en el discurso oral informativo. 
Caracterización textual y prosódica de tres tipos de palabras-clave en la noticia”. En BALSEBRE, A., PERONA, J. (eds.): Actas del I Congreso Publiradio: El Poder Creativo de la Palabra. Asociación científica de Investigación de las nuevas tecnologías de la comunicación. Icono 14. Revista de Comunicación y Nuevas tecnologías.

- (2010b): “Modelo Funcional de la Noticia Corporativa en Televisión”. Actas de II Congreso Internacional de Comunicación 3.0. Salamanca, 3-4 de octubre [en cartera].

NAVARRO TOMÁS, Tomás (1948, ed. 1974): Manual de entonación española. Madrid, Guadarrama.

PRINCE, Ellen F. (1988): “The ZPG Letter: Subjects, Definiteness, and Information-status”. URL:

ftp://babel.ling.upenn.edu/papers/faculty/ellen_prince/zpg.ps

RODERO ANTÓN, Emma (2003): Locución radiofónica. Madrid, Instituto Oficial de Radio y Televisión.

RODRÍGUEZ BRAVO, Ángel (2003): "La investigación aplicada: una nueva perspectiva para los estudios de comunicación”. Servei de publicacions de la UAB: Anàlisi. Quaderns de Comunicació i Cultura, No 30, pp. 17-36.

SHANON, Claude E, WEAVER, Warren (1981): Teoría Matemática de la Información. Madrid, Forka.

TABOADA, Maite, MANN, William C. (2005): “Applications of Rhetorical Structure Theory”. Discourse Studies 2005. En URL:

http://www.sfu.ca/rst/pdfs/Taboada_Mann_RST_Part2.pdf, [consultado el 19 de octubre de 2007]

- (2006): "Rhetorical Structure Theory: looking back and moving ahead". Discourse Studies 2006; 8; 423.

VAISSIÈRE, Jacqueline (1990): "Rhythm, accentuation and final lengthening in French”. En SUNDBERG, J., LENNART, L., y CARLSON, R. (1991): Music, language, speech, and brain. England, Macmillan Press in Houndmills.

VALLDUBÍ, Enric y VILKUNA, Maria (1998): “On Rheme and contrast”. Syntax and Semantics, 29: 79-108.

VAN DONZEL, Monique E., KOOPMANS-VAN BEINUM, Florien J. (1998): "Pitch accents, boundary tones, and information structure in spontaneous discourse in dutch". Athens, Greece. ISCA Archive.URL http://www.iscaspeech.org/archive [última consulta el 12 de marzo de 2008]

VAN DIJK, Teun A. (1990). La noticia como discurso: comprensión, estructura y producción de la información. Barcelona, Paidós.

XU, Yi (2004): “The Penta Model of Speech Melody: transmitting multiple communicative functions in parallel". From Sound to Sense: 50+ years of discoveries in speech communication. (pp. 91-96). Cambridge, MA. 